\title{
PUBLICACIONES, CONOCIMIENTO Y CIENCIA
}

\author{
PUBLICATIONS, KNOWLEDGE AND SCIENCE
}

\author{
DE LA OSSA V. JAIME, Dr. Sci.
}

Editor Revista Colombiana de Ciencias Animal - RECIA Universidad de Sucre, Facultad de Ciencias Agropecuarias, Colombia. Correspondencia: jaimedelaossa@yahoo.com

\begin{abstract}
Existen diversas editoriales que ofrecen el servicio de publicación de libros vía internet, se han vuelto muy populares debido a la masiva comunicación que envían y debido también a que muchos investigadores jóvenes o nuevos acogen esta vía rápida para ver sus textos publicados en un muy corto plazo. Operan de un modo muy particular, que implica primero la ubicación de tesis, disertaciones y trabajos de grado, trabajo que saben hacer sumamente bien; posteriormente se comunican por correo electrónico con el autor y le ofrecen la publicación del texto.
\end{abstract}

Pero aquí entran en gracia de discusión las siguientes dudas:

¿Cómo los derechos editoriales pasan a la Editorial?

Ya que casi siempre las tesis o trabajo de investigación son financiado o avalados por algún organismo público o privado, o la Universidad posee per se autoridad sobre ellos

¿Quién deberá asumir realmente y con primacía legal estos derechos?

No se hace referencia a los derechos morales, estos sin duda son del autor. No se debe olvidar que cuando una tesis o disertación ha sido aprobada, la Universidad ha invertido, al menos, en dirección y juzgamiento evaluativo, aspecto que no se estaría reconociendo.

De otro lado, queda una duda sobre las ganancias o posibles efectos económicos derivados de las tesis, se entiende que una tesis aporta novedad al conocimiento y es posible que de ella se deriven hallazgos que tiene valor tangible, quizá patentes. ¿Quién sería el dueño de esto, qué parte le correspondería al autor, qué parte a la Institución y cómo podrían reclamarlos?

Si bien es cierto que las exigencias académicas actuales implican que se deba publicar cada vez más y que las revistas especializadas poseen larga filas de espera, no es imposible hacerlo. Demanda más trabajo, es cierto, más aún si se le compara con la simple entrega del documento y en un santiamén se le ve en formato de libro, pero la prisa en asuntos de ciencia nunca ha sido buena consejera y menos aún si los filtros, ejecutados por serios editores y pares evaluadores desaparecen o se flexibilizan hasta casi no ser notorios. No se debe olvidar que las revistas académicas necesitan más de los autores que ellos de ellas (Wendy Lara Belcher). 
La difusión veloz de las editoriales en cuestión es un factor alucinante que deslumbra y no es que esto sea malo, pero las buenas revistas indexadas ya están en línea y cada vez un número mayor de ellas aboca por un sistema abierto, amplio y gratuito de divulgación. Si la idea es divulgar rápidamente, para eso existen los repositorios de tesis y disertaciones, en donde se pueden consultar y estudiar sin que los interesados pierdan sus derechos.

Por otro lado, las publicaciones académicas son muy diferentes a las publicaciones periodísticas o de novelas o de cuentos, el público de los artículos investigativos científicos es reducido, no se trata de escritos al alcance compresivo de todos. Los científicos están de acuerdo en que el conocimiento debe ser abierto y llegar a las masas, pero la ciencia actúa diferente, se trabaja en grupos reducidos de especialistas, podría decirse que no es democrática. Esta es una de las razones más poderosas para que los resultados de una tesis, que son valiosos, no queden perdidos en una montaña de publicaciones variadas, es necesario que vayan al lugar que la ciencia les ha señalado, que no es otro que las revistas académicas, en donde si expresarían sus más altos valores. 